DOI 10.37882/2223-2982.2021.01.25

\title{
ХАРАКТЕРИСТИКА ПИЩЕВОГО ПОВЕДЕНИЯ И ПИЩЕВОГО СТАТУСА СПОРТСМЕНОВ, СПЕЦИАЛИЗИРУЮЩИХСЯ В ЛЕГКОЙ АТЛЕТИКЕ
}

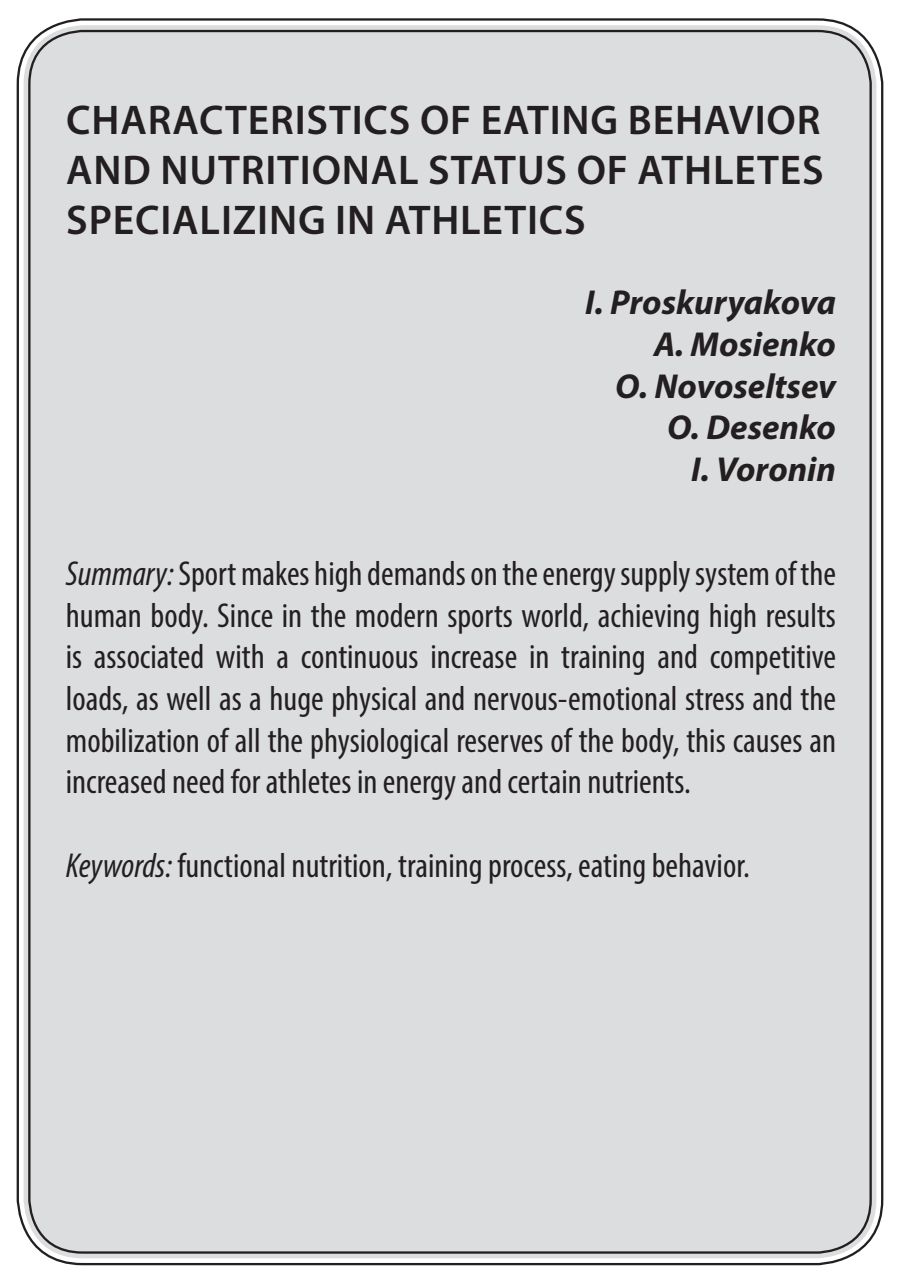

$\mathrm{C}$ овременный спорт включает виды с различным проявлением основных физических качеств - силы, быстроты, выносливости, гибкости и ловкости. Высокие спортивные результаты связаны с различными уровнями развития этих качеств и характеризуются метаболическими изменениями обмена веществ, по которым можно составить представление о механизмах энергообеспечения мышечной деятельности. Среди многочисленных условий внешней среды, постоянно воздействующих на организм спортсмена, ведущее место занимает фактор питания [1].

Поставленные в работе задачи решались поэтапно в осенне - зимний период 2018-2019г.

Организация исследования включала 4 этапа:

- проведение анализа отечественной и зарубежной научно-методической литературы по изучаемой
Проскурякова Ирина Петровна

Преподаватель, Кубанский государственный медицинский университет, г. Краснодар

irina-grebenyova@yandex.ru

Мосиенко Александра Игоревна

Учитель, ГБОУ КК ШИПС, г. Краснодар ponikarenko90@mail.ru

Новосельчев Олег Николаевич Преподаватель, Кубанский государственный медицинский университет, г. Краснодар masterdamas@mail.ru

Десенко Ольга Петровна

Преподаватель, Кубанский государственный медицинский университет, г. Краснодар peleton5@mail.ru

Воронин Илья Сергеевич

Преподаватель, Кубанский государственный медицинский университет, г. Краснодар

Voronin05.04.1990@mail.ru

Аннотация: Спорт предъявляет высокие требования к энергообеспечивающей системе организма человека. Так как в современном спортивном мире достижение высоких результатов связано с непрерывным повышением тренировочных и соревновательных нагрузок, а также огромным физическим и нервно-эмоциональным напряжением и мобилизацией всех физиологических резервов организма, это обуславливает повышенную потребность спортсменов в энергии, отдельных пищевых веществах.

Ключевые слова: функциональное питание, тренировочный процесс, пищевое поведение.

проблеме и разработка общей схемы исследования; подбор группы спортсменов, специализирующихся в легкой атлетике (бег на $100-3000$ м) и имеющих спортивный стаж;

- комплексное обследование, а также выявление особенностей энергетической направленности тренировочных занятий;

- проведение мониторинга пищевого поведения обследуемых и их отношения к спортивному питанию;

- характеристика пищевого статуса спортсменов с позиции интегрального показателя биохимической и физиологической адекватности базового питания, учитывающего его эссенциальные компоненты.

В исследовании участвовали легкоатлеты 16-25 лет, занимающиеся в СДЮСШОР по легкой атлетике г. Крас- 
нодара. Все участники исследования имели разную квалификацию - от 2-го взрослого разряда до мастера спорта. Спортсмены имели разный пол, и все занимались легкой атлетикой не менее 3-х лет.

Обследование легкоатлетов проводилось в предсоревновательном периоде годичного тренировочного цикла. По результатам медицинского обследования все спортсмены допущены к занятиям. В период исследования спортсмены питались в домашних условиях и тренировались регулярно по единому плану у одного тренера.

В работе использовались следующие методы исследования:

- проведение мониторинга пищевого поведения спортсменов, интервьюирование;

- определение суточных энерготрат и энергетической направленности тренировочных нагрузок;

- индивидуальная оценка адекватности пищевого статуса спортсменов и его биохимическая характеристика;

- статистический анализ экспериментальных данных.

По характеру участия различных механизмов в энергообеспечении тренировочные занятия легкоатлетов различной специализации имеют отличия, которые были установлены путём хронометража. Тренировочные занятия по характеру энергообеспечения включали следующие виды нагрузки:

- для стайеров: алактатная- $5 \%$ у легкоатлетов, специализирующихся в беге на длинные дистанции (стайеры);

- для спринтеров 20\%- у легкоатлетов, специализирующихся на короткие дистанции (спринтеры), анаэробно - гликолитическая- 60\%, анаэробно аэробная- $15 \%$.

Полученные результаты свидетельствуют, что тренировочные занятия у легкоатлетов имеют преимущественно анаэробно - гликолитическую направленность, что связано с преобладанием в тренировках таких видов элементов, как работа предельной мощности, особенно для спринтеров. При этом по участию основных источников энергообеспечения тренировочные занятия легкоатлетов разной внутривидовой специализации имели отличия в соотношении алактатного и аэробного компонентов специальной работоспособности.

Адекватность энергообеспечения мышечной деятельности в значительной степени зависит от индивидуального пищевого поведения, поэтому целесообразно рассмотреть отношение спортсменов к проблеме питания, и, в частности, к использованию в режиме питания функциональных продуктов.

Маркетинговые исследования, проводили с участием спортсменов, специализирующихся в легкой атлетике. Участники анкетирования заполняли разработанные нами анкеты. Опрошено 40 человек (20 мужчин и 20 женщин) в возрасте от 16 до 25 лет, занимающихся в скоростно-силовых видах и в видах на выносливость, квалификации от 2-го взрослого разряда до мастеров спорта и различной специализации.

Необходимость рассмотрения некоторых характеристик этой группы потребителей биологически активных добавок будет полезной для понимания роли функционального питания в жизни людей, занимающихся физической культурой и спортом. Общеизвестно, что у спортсменов энергетические затраты очень высокие и не всегда их можно возместить потреблением обычных пищевых продуктов, сохраняя при этом оптимальное соотношение между основными компонентами питания. В связи с этим важным является рассмотрение основных характеристик потребителей и предпочитаемых видов спортивного питания.

Результаты опроса показали, что высокую спортивную квалификацию имеют 30\% (12 мастеров спорта), среднюю квалификацию 60\% (14 кандидатов в мастера спорта) и 10 спортсменов, имеющих 1-ый взрослый разряд) и 10\% имеют низкую квалификацию (2-ой взрослый разряд) (рис. 1).

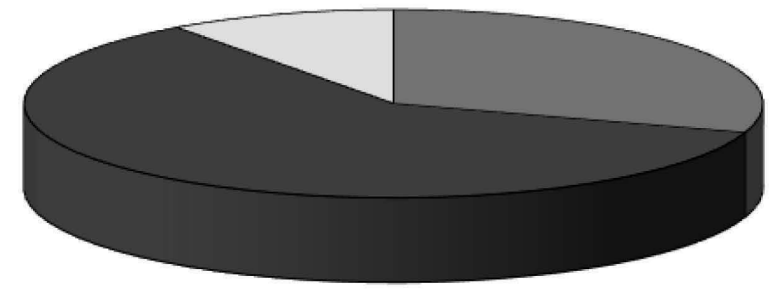

\author{
口мастера спорта \\ 口Кандидат в мастера спорта и 1-ый \\ взр. разряд \\ 口2-ой взр. разряд
}

Рис.1. Спортивная квалификация спортсменов, принимавших участие в анкетировании 
На основании данных анкетного опроса выявлено, что стаж занятий спортом у исследуемых колеблется от 2 до 11 лет.

Исследование показало несколько общих особенностей отношения спортсменов к своему питанию. Так, оказалось, что представление о высокой значимости здорового питания во всех группах обследуемых сочетается с высоким уровнем представлений о том, что такое «Функциональное питание»- 35\% респондентов знакомы с этим понятием, а 65\% не имеют понятия.

Необходимо отметить, что под функциональным питанием понимается использование в питании пищевых добавок и продуктов повышенной биологической ценности, содержащих нетрадиционные природные биологически активные низкомолекулярные факторы пищи.

Их применение предполагает направленное воздействие на ведущие метаболические звенья энергетического обмена, что обеспечивает повышение общей и специальной работоспособности спортсменов, а также ускорение процессов восстановления, регидратацию организма во время и после выполнения физических нагрузок и др. [1].

Результаты анкетирования выявили, что полностью информированы о рациональном питании 45\% опрошенных, не очень информированы 55\%, совсем неинформированных не оказалось.

В настоящее время в спортивных магазинах и предлагаемых дистрибьюторами различных фирм можно обнаружить свыше 150 наименований спортивного питания. Однако нельзя говорить о равномерности их потребления спортсменами. Приведённые ниже данные показывают специфическую структуру потребления видов спортивного питания.

Результаты маркетингового исследования показали, что систематически потребляют спортивное питание $80 \%$, не употребляют $20 \%$.

Основными причинами, по которым 20\% опрошенных не употребляют спортивное питание, по их мнению, являются: высокая цена, низкое качество и негативное влияние на здоровье (рис. 2).

Основными критериями выбора спортивного питания 50\% респондентов считают эффективность питания и в меньшей степени учитывают при покупке продукции ее цену и марку производителя, таких только 12\%. При этом около $38 \%$ респондентов при выборе питания учитывают советы тренера и коллег (рис. 3).

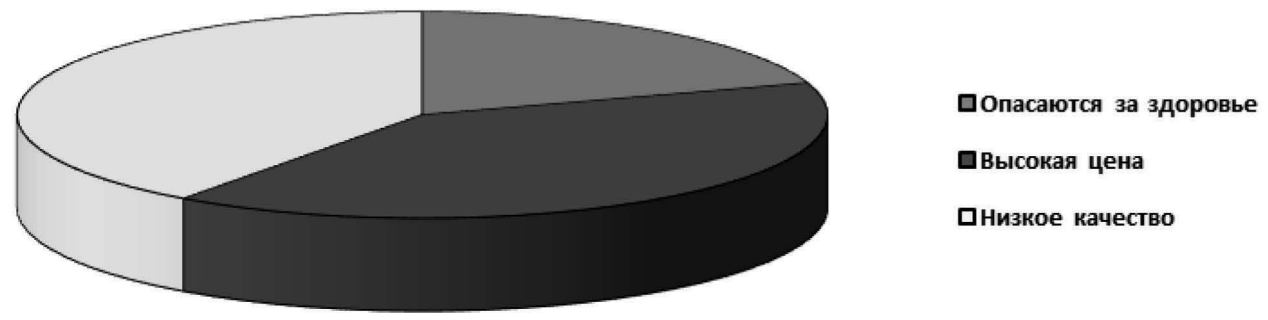

Рис.2. Причины, по которым спортсмены не употребляют спортивное питание

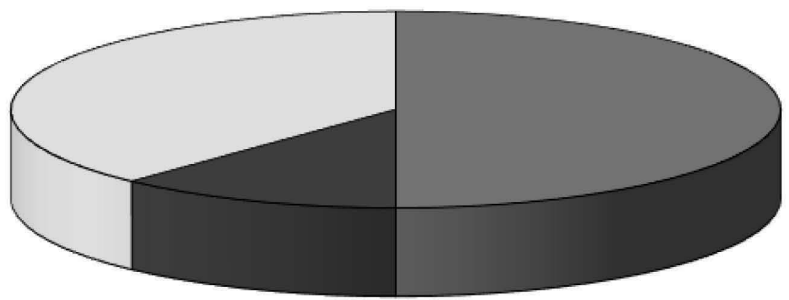

\author{
口эффективность питания \\ 口цена и марка производителя
}

口Совет тренера и коллег

Рис.3. Критерии выбора спортивного питания 
Учитывая, что потребление функционального питания наиболее распространено среди спортсменов, мы проанализировали потребление биологически активных добавок различной химической направленности. Наибольшее предпочтение респонденты отдают биодобавкам углеводной направленности 26\%, а также белковой (протеин) - 21\%, а в меньшей степени витаминам и витаминно-минеральным комплексам - по 11\%, креатинсодержащим добавкам- 10\%, а также свободным аминокислотам - всего 5\%.

Такое массовое потребление протеинов и углеводных смесей обусловлено тем, что спортсмены убеждены - образование специфических структурных и ферментных белков обуславливает достигаемый тренировочный эффект нагрузки, что напрямую связано с приростом показателей спортивной работоспособности. Кроме того, эргогенические эффекты от употребления в процессе питания спортсменов повышенных количеств белковых продуктов связаны с участием белков и аминокислот в анаболическом обмене, способствующем обновлению белковых структур тела, увеличением мышечной массы, повышением силы и мощности, что очень важно в силовых видах спорта. Также потребление углеводных смесей в процессе тренировки повышает энергетический потенциал спортсмена, что соответственно позволяет тренироваться дольше и интенсивнее.

Участники исследования сформулировали следующие причины потребления спортивного питания:

- для увеличения спортивного результата. Этот довод является основным для 44\% опрошенных. Показательно, что этот аргумент является определяющим для респондентов вне зависимости от пола, возраста, уровня дохода.

- для общего укрепления организма. На первое место такой аргумент выдвинули 31\% опрошенных, большая часть из которых не стремится к достижению высоких спортивных результатов.

- для наращивания мышечной массы. Является наиболее важным для 25\% респондентов. Этот фактор более важен для мужчин, чем женщин.

- для похудения. Среди респондентов этот аспект не выделили, возможно, масса тела их соответствует физиологической норме.

Исследования показали, что продукты спортивного питания импортного производства потребляют 100\% опрошенных спортсменов.

Затраты на спортивное питание составляют у 50\% опрошенных от 1000 до 2000 рублей в месяц, у 13\% более 2000 рублей, у 37\% до 1000 рублей.

Широкое разнообразие продукции практически полностью удовлетворяет требования покупателей. На вопрос: «Вас удовлетворяет ассортимент и качество спортивного питания?» 56\% потребителей ответили, что их всё устраивает, 38\% опрошенных ответили, что они не совсем удовлетворены и лишь 6\% потребителей не удовлетворены имеющимся ассортиментом и качеством биологически активных добавок.

Результаты исследования показывают, что несмотря на не самую благоприятную социально-экономическую обстановку в стране, потребление спортивного питания остаётся на высоком уровне (80\% респондентов потребляют подобные продукты). Этому способствуют эффективность питания и быстрота приготовления, а также ценовая доступность этой категории продуктов для спортсменов.

Основным путём реализации спортивного питания в Краснодарском крае являются спортивные магазины, которые в основном расположены при спортивных клубах и спорткомплексах. Важным направлением дальнейшего развития сферы производства и сбыта спортивного питания является создание технологической базы производства отечественных продуктов спортивного питания.

Таким образом, представляется необходимым изучить пищевой статус легкоатлетов, особый интерес в котором представляют такие эссенциальные вещества как незаменимые аминокислоты, жирные кислоты различной степени насыщения, витамины, макро- и микроэлементы, адекватность которых в значительной степени определяется дополнительным введением в рационы продуктов функционального назначения.

Для проведения анализа, с использованием компьютерной программы «Диета ФП», разработанной профессором Н.К. Артемьевой, нами были просчитаны 280 базовых рационов питания [2]. Хотя по энергетической ценности суточные рационы практически удовлетворяли энерготратам спортсменов, интегральный показатель составлял всего $60 \%$, что указывает на достоверно значимый дисбаланс отдельных нутриентов.

Как показали данные аналитического расчета, все незаменимые аминокислоты находятся в дефиците, избыток характерен только для триптофана (таблица 1).

Что касается жирных кислот, то насыщенные жирные кислоты находятся в избыточном состоянии, а мононенасыщенные и полиненасыщенные (линоленовая и арахидоновая) имеют значимый дефицит (таблица 2).

Среднесуточное потребление витаминов в условиях неорганизованного питания спортсменов представлено в таблице 3. 
Таблица 1.

Характеристика аминокислотного состава пищевого статуса спортсменов

\begin{tabular}{|l|c|c|}
\multirow{2}{*}{\multicolumn{1}{c|}{ Аминокислоты незаменимые }} & Количество, г & \% \\
\cline { 2 - 3 } & M & о \\
\hline Валин & $6,3 \pm 0,4$ & $-8,2$ \\
\hline Изолейцин & $5,2 \pm 0,3$ & $-23,8$ \\
\hline Лейцин & $7,2 \pm 0,9$ & $-32,7$ \\
\hline Лизин & $8,3 \pm 0,6$ & $-2,4$ \\
\hline Серосодержащие: метионин + цистин & $4,1 \pm 0,2$ & $-65,0$ \\
\hline Ароматические: фенилаланин +тирозин & $8,9 \pm 1,0$ & $-46,8$ \\
\hline Треонин & $4,8 \pm 0,3$ & $-7,6$ \\
\hline Триптофан & $1,6 \pm 0,1$ & $+33,3$ \\
\hline Сумма н/з аминокислот & $46,4 \pm 3,0$ & $-30,0$ \\
\hline Соотношение: триптофан/лизин/метионин+цистин & $1: 5,2: 2,6$ & $1: 4: 6$ \\
\hline
\end{tabular}

*- за N приняты количества, разработанные Институтом Питания РАМН.

Таблица 2.

Содержание жирных кислот в рационах неорганизованного питания спортсменов, специализирующихся в легкой атлетике.

\begin{tabular}{|l|c|c|}
\multirow{2}{*}{\multicolumn{1}{c|}{ Жирные кислоты }} & Количество, г & \% \\
\cline { 2 - 3 } & от N*
\end{tabular}

*3а норму приняты должные суточные потребности в жирных кислотах спортсменов, специализирующихся в легкой атлетике в соответствии с фактическими энерготратами; (-) дефицит, (+) избыток жирных кислот в рационах [3].

Таблица 3.

Характеристика витаминного состава пищевого статуса спортсменов

\begin{tabular}{|c|c|c|}
\hline \multirow{2}{*}{ Витамины } & Количество, г & \multirow{2}{*}{$\begin{array}{c}\% \\
\text { от N* }\end{array}$} \\
\hline & $M \pm m, r$ & \\
\hline Ретинол & $0,57 \pm 0,09$ & $-48,6$ \\
\hline В- каротин & $1,26 \pm 0,61$ & $-62,3$ \\
\hline Ретинол + $\beta$ - каротин & $1,83 \pm 0,70$ & $-41,1$ \\
\hline Ретиноловый эквивалент & 0,78 & $-75,7$ \\
\hline Соотношение: рет./ $\beta$ - кар. & $31: 69$ & $33: 67$ \\
\hline Тиамин & $1,15 \pm 0,06$ & $-66,0$ \\
\hline Рибофлавин & $1,27 \pm 0,28$ & $-68,8$ \\
\hline Ниацин & $12,91 \pm 1,71$ & $-58,7$ \\
\hline Ниациновый эквивалент & $32,90 \pm 2,77$ & $+2,5$ \\
\hline Аскорбиновая кислота & $72,27 \pm 9,99$ & $-61,4$ \\
\hline
\end{tabular}

*За норму принято рекомендуемое количество витаминов [4]. 
Результаты расчета суточного потребления витаминов спортсменами при неорганизованном питании показали, что причина низкой сбалансированности витаминов в рационах спортсменов заключается в значительном недостатке всех витаминов, за исключением ниацина, который при суммировании его с эквивалентным количеством триптофана во всех рационах показал избыток.

Результаты анализа минерального состава рационов неорганизованного питания спортсменов, представленные в таблице 4, обнаружили дефицит практически всех исследуемых нутриентов.

Наиболее значимый дефицит обнаружен в суточном потреблении кальция и железа. В общем же, результаты исследования показали, что фактическое питание спортсменов до настоящего времени далеко от принципов сбалансированного. Так, подавляющее большинство рационов не удовлетворяет суточным потребностям спортсменов в основных и незаменимых пищевых веществах: характерным является дефицит витаминов и минеральных веществ, избыток насыщенных жирных кислот, что обуславливает низкий интегральный показатель адекватности и дисбаланс химического состава.

Самостоятельная организация рационального питания осложняется отношением самого спортсмена, находящегося под влиянием различных «гастрономических» обычаев и привычек, которые исходят из семьи и личных традиций. В результате обнаружены серьезные нарушения режима при неорганизованном питании спортсменов. В частности, около 40 \% легкоатлетов принимали пищу 2 раза в день (вместо рекомендуемых 4 раз), несмотря на то что оптимальная кратность питания позволяет создать выгодные для организма условия протекания обмена веществ, и легче адаптироваться к любым стрессовым воздействиям. Часто от- мечались случаи несоблюдения физиологически правильных интервалов между приемами пищи, началом и окончанием тренировки. Установлено нерациональное распределение калорийности суточных рационов и основных пищевых веществ между отдельными приемами пищи. Так, при низкокалорийном завтраке спортсмены обильно обедали, а при недостаточном по калорийности обеде - плотно ужинали. Практически каждый набор продуктов (блюд) для одновременного приема был составлен без учета совместимости продуктов, что, несомненно, сказывалось на усвояемости отдельных пищевых веществ.

Обобщая собственные и литературные данные, следует сделать вывод о необходимости индивидуального подхода к организации рационального питания, что согласуется с рекомендациями Всемирной организации Здравоохранения.

Поэтому к числу важнейших задач специалистов - нутрициологов относятся:

1. своевременное выявление устойчивых тенденций в потреблении отдельных продуктов и пищевых веществ спортсменами;

2. оптимизация калорийности и химического состава рационов по принципу изменения весового соотношения входящих в их состав традиционных пищевых продуктов;

3. коррекция питания биологически активными веществами с целью создания выгодного метаболического фона для реализации тех конкретных педагогических задач, которые стоят перед спортсменами.

Мониторинг пищевого поведения спортсменов свидетельствует о том, что, фактическое питание спортсменов до настоящего времени далеко от принципов сбалансированного. Так, подавляющее большинство ра-

Таблица 4.

Характеристика минерального состава пищевого статуса спортсменов.

\begin{tabular}{|l|c|c|}
\multirow{2}{*}{\multicolumn{1}{c|}{ Минеральные вещества }} & Количество, г & \multirow{2}{*}{$\begin{array}{c}\% \\
\text { от } \mathrm{N}^{*}\end{array}$} \\
${$\cline { 2 - 3 }$} }$ & $\mathrm{M} \pm \mathrm{m}, \mathrm{r}$ & $-8,0$ \\
\hline Калий & $4760 \pm 130$ & $-2,8$ \\
\hline Соотношение K:Na & $3222 \pm 180$ & $1: 2$ \\
\hline Кальций & $1: 1,5$ & $-51,3$ \\
\hline в т.ч молочный & $620 \pm 23$ & $-0,2$ \\
\hline Магний & $399 \pm 23$ & $-25,8$ \\
\hline Фосфор & $304 \pm 28$ & $-23,7$ \\
\hline Железо & $1264 \pm 120$ & $-41,1$ \\
\hline в т.ч. гемовое & $15,9 \pm 0,3$ & - \\
\hline Соотношение Ca:Mg:P & $3,3 \pm 0,1$ & $1: 0,5: 1,5$ \\
\hline
\end{tabular}

*За норму принято рекомендуемое количество минеральных веществ [5]. 
ционов не удовлетворяет суточным потребностям спортсменов в основных и незаменимых пищевых веществах: характерным является дефицит витаминов и минеральных веществ, избыток насыщенных жирных кислот, что обуславливает низкий интегральный показатель адекватности и дисбаланс химического состава.

Распределение энергозатрат обследуемых по видам деятельности в течение суток наглядно указывает, что наибольшее вовлечение энергетического обмена в процессы метаболизма, наблюдается при выполнении специфических нагрузок на тренировочных занятиях. В процессе развития специальной выносливости лег- коатлетов преобладают нагрузки анаэробной направленности, причем вечерние тренировки отличаются повышенным содержанием упражнений алактатного и лактатного характера. Эта закономерность требует особого подхода к разработке методов коррекции нутриционного статуса организма спортсменов.

Коррекция энергетического баланса и пищевого статуса спортсменов должна носить индивидуальный характер, учитывать адекватность фактических базовых рационов, энергетическую направленность тренировочных нагрузок и особенности метаболических сдвигов при работе и в период восстановления.

\section{ЛИТЕРАТУРА}

1. Артемьева Н.К. Принципы организации функционального питания в условиях напряженной мышечной деятельности.- Социально-гигиенический мониторинг здоровья/ Мат. 3-ей научно- практической конференции- Рязань.- 2004.-с.233.

2. Артемьева Н.К. Автоматизированная система «Диета ФП» Свидетельство 06 официальной регистрации программы.-Москва.-2009.-52с.

3. Пшендин А.И. Рациональное питание спортсменов. М., 2005. 76 с.

4. Гриффит Х.В. Витамины, травы, минералы и пищевые добавки: Справочник, - М.: ФАИР ПРЕСС, 2000.- 1056с.

5. Семенов В.А. Лекарственные средства в спорте. -Москва, -2012. - 67-69 с.

( П Проскурякова Ирина Петровна (irina-grebenyova@yandex.ru ), Мосиенко Александра Игоревна (ponikarenko90@mail.ru ), Новосельцев Олег Николаевич (asterdamas@mail.ru ), Десенко Ольга Петровна (peleton5@mail.ru ),

Воронин Илья Сергеевич (Voronin05.04.1990@mail.ru).

Журнал «Современная наука: актуальные проблемы теории и практики»

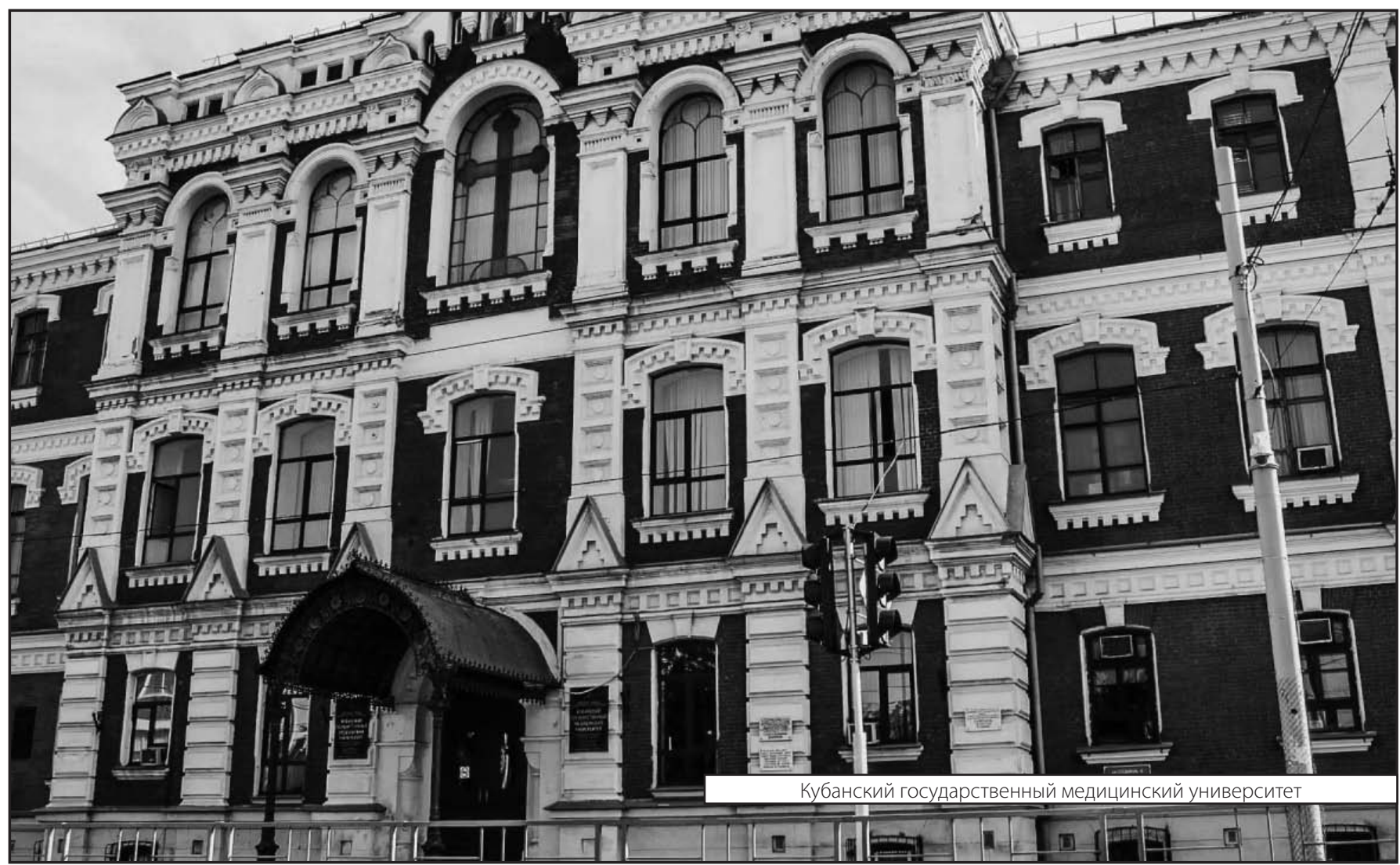

